\title{
Cu-Au/rGO Nanoparticle Based Electrochemical Sensor for 4- Chlorophenol Detection
}

\author{
Yajing Yang, Ning Ma, Zhaoyong Bian* \\ College of Water Sciences, Beijing Normal University, Beijing 100875, PR China \\ *E-mail: bian@bnu.edu.cn
}

doi: $10.20964 / 2019.05 .04$

Received: 5 January 2019 / Accepted: 19 February 2019 / Published: 10 April 2019

Copper, gold or gold/copper nanoparticles loaded on reduced graphene oxide $(\mathrm{Cu} / \mathrm{rGO}, \mathrm{Au} / \mathrm{rGO}$ and $\mathrm{Cu}-$ $\mathrm{Au} / \mathrm{rGO}$ ) were synthesized as catalysts, using chemical and fractional reduction processes. These materials were characterized by scanning electron microscopy, X-ray diffraction, transmission electron microscopy, Fourier transform infrared spectroscopy and X-ray photoelectron spectroscopy. A series of sensitive 4-chlorophenol (4-CP) sensors were fabricated using electrodes modified with these three catalysts. The impedance values of these devices were assessed using an alternating current impedance method, while the detection of 4-CP was investigated by cyclic voltammetry. The $\mathrm{Cu}-\mathrm{Au} / \mathrm{rGO}$ exhibited the best catalytic properties. Under optimized conditions ( $\mathrm{pH} 6.5$, scan rate $100 \mathrm{mV} / \mathrm{s}$ ), a sensor based on a glassy carbon electrode modified with this material exhibited a low 4-CP detection limit of 0.17 $\mu \mathrm{mol} / \mathrm{L}$, and demonstrated good reproducibility and long-term stability. This sensor has high application value in on-line detection of chlorophenol pollutants in wastewater.

Keywords: $\mathrm{Cu}$-Au/graphene; glassy carbon electrode; 4-chlorophenol wastewater; electrochemical detection

\section{FULL TEXT}

(C) 2019 The Authors. Published by ESG (www.electrochemsci.org). This article is an open access article distributed under the terms and conditions of the Creative Commons Attribution license (http://creativecommons.org/licenses/by/4.0/). 